\title{
FOXG1 improves mitochondrial function and promotes the progression of nasopharyngeal carcinoma
}

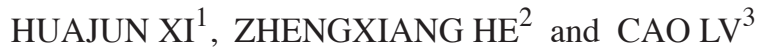 \\ ${ }^{1}$ Department of Otolaryngology and Stomatology, Shouguang People's Hospital, Shouguang, Shandong 262700; ${ }^{2}$ Department of \\ Otolaryngology and Maxillofacial Surgery, Wuwei People's Hospital, Wuwei, Gansu 733000; ${ }^{3}$ Department of Otolaryngology, \\ Head and Neck Surgery, The Second Affiliated Hospital of Kunming Medical University, Kunming, Yunnan 650101, P.R. China
}

Received October 10, 2020; Accepted May 14, 2021

DOI: $10.3892 / \mathrm{mmr} .2021 .12290$

\begin{abstract}
Forkhead-box gene 1 (FOXG1) has been reported to serve an important role in various malignancies, but its effects on nasopharyngeal cancer (NPC) remain unknown. Thus, the present study aimed to investigate the specific regulatory relationship between FOXG1 and NPC progression. Tumor tissues and matching para-carcinoma tissues were obtained from patients with NPC. Small interfering (si) RNA-FOXG1 and pcDNA3.1-FOXG1 were transfected into SUNE-1 and C666-1 cells to knockdown and overexpress FOXG1 expression, respectively. FOXG1 expression was detected using reverse transcription-quantitative PCR and immunohistochemistry. Cell proliferation was detected using MTT and 5-ethynyl-20-deoxyuridine assays. Transwell invasion assay, wound healing assay and flow cytometry were used to detect cell invasion, migration and apoptosis, respectively. Western blotting was conducted to detect the expression levels of mitochondrial markers (succinate dehydrogenase complex flavoprotein subunit A, heat shock protein 60 and pyruvate dehydrogenase), epithelial-mesenchymal transition (EMT) related proteins (N-cadherin, Snail and E-cadherin) and apoptosis-related proteins [Bax, Bcl-2, poly(ADP-ribose) polymerase 1 (PARP), cleaved PARP, cleaved caspase-3, cleaved caspase-8, cleaved caspase- 9 , caspase-3, caspase- 8 and caspase-9]. The mitochondrial membrane potential was detected via flow cytometry, while the ATP/ADP ratio was determined using the ADP/ATP ratio assay kit. The present
\end{abstract}

Correspondence to: Dr Cao Lv, Department of Otolaryngology, Head and Neck Surgery, The Second Affiliated Hospital of Kunming Medical University, 374 Dianmian Avenue, Wuhua, Kunming, Yunnan 650101, P.R. China

E-mail:kmlvcao@163.com

Abbreviations: FOXG1, forkhead-box gene 1; NPC, nasopharyngeal cancer;IHC,immunohistochemistry; RT-qPCR,reverse transcriptionquantitative PCR; MMP, mitochondrial membrane potential; EMT, epithelial-mesenchymal transition

Key words: FOXG1, NPC, mitochondria, proliferation, EMT results demonstrated that FOXG1 expression was upregulated in NPC tissues and cells, and was associated with distant metastasis and TNM stage. Moreover, knockdown of FOXG1 inhibited the proliferation, migration, invasion, EMT and mitochondrial function of SUNE-1 cells, as well as promoted cell apoptosis, while the opposite results were observed in C666-1 cells. In conclusion, FOXG1 enhanced proliferation, migration and invasion, induced EMT and improved mitochondrial function in NPC cells. The current findings provide an adequate theoretical basis for the treatment of NPC.

\section{Introduction}

Nasopharyngeal carcinoma (NPC) is a malignant tumor, which is rare in most parts of the world, but relatively common in Southeast Asia, North Africa and Southern China $(1,2)$. In 2012, there were $~ 86,700$ new cases and 50,800 deaths associated with NPC worldwide (3). A variety of risk factors, such as environmental factors, genetic variation and Epstein-Barr virus (EBV) infection, are associated with the occurrence of NPC (4). In recent years, due to the limitations of surgery, radiotherapy and chemotherapy remain the most promising and effective treatments for early-stage NPC (5). Although improvements in treatment methods have increased survival, some patients with advanced NPC develop distant metastasis with poor prognosis (6). Therefore, further understanding of the molecular mechanisms involved in the progression of NPC may provide a new direction for the therapeutic efficiency of NPC.

Forkhead-box gene 1 (FOXG1), a member of the forkhead box family of transcription factors, is often specifically expressed in human brain tissue and is associated with the developmental lesions of the nervous system (7-9). Previous studies have reported that FOXG1 expression was upregulated in several cancer types, such as hepatoblastoma (10), ovarian cancer (11) and glioblastoma (12), and upregulation of FOXG1 was positively correlated with high tumor grade, suggesting that FOXG1 may be an oncogene (13). However, there is little knowledge regarding the role of FOXG1 in NPC, which requires further study.

Uncontrolled cell energetics are a feature of malignant cancer cells $(14,15)$. Mitochondria are the main cellular sites of energy production (16). Changes in the structure and 
function of mitochondria in tumor cells lead to an increase in the absorption and utilization of glutamine, thereby meeting the bioenergy requirements of tumor cells, which is known as tumor mitochondrial metabolic reprogramming (17). Accumulating evidence has revealed that mitochondria serve an important role in cancer metabolism, proliferation, apoptosis and metastasis $(18,19)$. However, the specific regulatory relationship between FOXG1 and NPC progression remains unknown.

The present study investigated the effects of FOXG1 on NPC progression and further examined its role in cell proliferation, apoptosis, migration, invasion and mitochondrial function. The results of the current study may provide a foundation for the treatment of NPC.

\section{Materials and methods}

Bioinformatics analysis. The mRNA expression profiles were obtained from Gene Expression Omnibus (GEO) dataset website (ncbi.nlm.nih.gov/geo/). GSE12452 was used to analyze the mRNA expression of FOXG1 in NPC tissues and normal tissues. FOXG1 mRNA expression data was processed using the $\mathrm{R}$ software (3.4.0 version, r-project.org/) and limma $\mathrm{R}$ package (20).

Tissue samples. A total of 70 NPC tumor tissues and matching para-carcinoma tissues were obtained from the Department of Otolaryngology-Head and Neck Surgery, The Second Affiliated Hospital of Kunming Medical University between January 2018 and March 2020. The inclusion criteria were as follows: i) Patients had never received radiotherapy or chemotherapy before surgery; ii) patients had no medical history of other malignant tumors; and iii) the diagnosis of all samples was confirmed by histopathology of NPC. The exclusion criteria were: i) Patients had incomplete clinicopathological data; and ii) patients were unwilling to cooperate with treatment. The collected samples were immediately frozen in liquid nitrogen after surgical resection and stored at $-80^{\circ} \mathrm{C}$ until use in subsequent assays. The study was approved by the Ethics Committee of The Second Affiliated Hospital of Kunming Medical University (approval no. KYDE201801012), and all patients (20 females and 50 males; age, 28-75 years) signed informed consent forms.

Immunohistochemistry (IHC). First, 10\% neutral buffered formalin was used to fix the tissue samples for $24 \mathrm{~h}$ at room temperature, which were then dehydrated and embedded in paraffin wax. Next, the paraffin-embedded samples were cut into $4-\mu \mathrm{m}$ thick sections, and the sections were dewaxed with xylene. They were then dehydrated with gradient ethanol, and endogenous enzymes were removed with $3 \% \mathrm{H}_{2} \mathrm{O}_{2}$ for $10 \mathrm{~min}$ at room temperature. Subsequently, the sections were treated with $10 \mathrm{mM}$ Tris-EDTA (Thermo Fisher Scientific, Inc.) at $125^{\circ} \mathrm{C}$ in a pressure cooker for antigenic retrieval and then incubated with primary antibody (FOXG1; 1:200; cat. no. ab196868; Abcam) overnight at $4^{\circ} \mathrm{C}$, followed by incubation with goat anti-rabbit secondary antibody $(1: 250$; cat. no. ab150081; Abcam) for $30 \mathrm{~min}$ at room temperature. Finally, the sections were stained with 3, 3'-diaminobenzidine (Thermo Fisher Scientific, Inc.) for $5 \mathrm{~min}$ at room temperature, counterstained with hematoxylin for $3 \mathrm{~min}$ at room temperature and mounted with neutral gum. Images were captured using an Olympus FV1000 laser scanning confocal microscope (Olympus Corporation; magnification, x100 and x400).

Cell culture. Human immortalized nasopharyngeal epithelial cells (NP69; BeNa Culture Collection; Beijing Beina Chunglian Institute of Biotechnology) were cultured in a keratinocyte/serum-free medium (Gibco; Thermo Fisher Scientific, Inc.) supplemented with $0.2 \mathrm{ng} / \mathrm{ml}$ human recombinant epidermal growth factor, 2\% FBS (Gibco; Thermo Fisher Scientific, Inc.) and $1 \%$ streptomycin and penicillin (Gibco; Thermo Fisher Scientific, Inc.). The NPC cells (C666-1 and SUNE-1; The Cell Bank of Type Culture Collection of Chinese Academy of Sciences) were cultured in RPMI-1640 medium (Gibco; Thermo Fisher Scientific, Inc.) containing 5\% FBS and $1 \%$ streptomycin and penicillin. Both cells were grown in an incubator with $5 \% \mathrm{CO}_{2}$ at $37^{\circ} \mathrm{C}$.

Cell transfection. SUNE-1 cells were divided into four groups: Control (without treatment), small interfering (si) RNA-negative control (siNC; cells transfected with $5 \mu \mathrm{g}$ non-targeting siRNAs), sil-FOXG1 (cells transfected with $5 \mu \mathrm{g}$ sil-FOXG1; 5'-GCCCTTCAGTTCAGGTACAAT-3') and si2-FOXG1 (cells transfected with $5 \mu \mathrm{g}$ si2-FOXG1; 5'-GGCTGTTTACCCACAATGAAA-3'). C666-1 cells were divided into three groups: Control (without treatment), pcDNA3.1-NC (cells transfected with $4 \mu \mathrm{g}$ pcDNA3.1-NC vector) and pcDNA3.1-FOXG1 (cells transfected with $4 \mu \mathrm{g}$ pcDNA3.1-FOXG1 vector). Cells ( $1 \times 10^{5}$ cells/well) were seeded into 12-well plates and transfected using Lipofectamine ${ }^{\circledR} 3000$ reagent (Invitrogen; Thermo Fisher Scientific, Inc.) at $37^{\circ} \mathrm{C}$. The pcDNA3.1-FOXG1, siRNA-FOXG1 and NCs were purchased from Guangzhou RiboBio Biotech Co., Ltd. At 48 h post-transfection, subsequent experiments were performed.

Reverse transcription-quantitative PCR (RT-qPCR). The relative $\mathrm{mRNA}$ expression level of FOXG1 and mitochondrial DNA (mtDNA) copy number was measured via RT-qPCR. TRIzol $^{\circledR}$ reagent (Invitrogen; Thermo Fisher Scientific, Inc.) was used to extract total RNA from tissues and cells, and a Prime-Script ${ }^{\mathrm{TM}}$ reverse transcription kit (Takara Bio, Inc.) was used to synthesize cDNA according to the manufacturer's instructions. The SYBR-Green PCR kit (Takara Bio, Inc.) was used to perform RT-qPCR on a 7500 Fast Real-Time PCR system (Applied Biosystems; Thermo Fisher Scientific, Inc.). The RT-qPCR procedure was as follows: Initial denaturation at $94^{\circ} \mathrm{C}$ for $2 \mathrm{~min}$, followed by 40 cycles of denaturation at $94^{\circ} \mathrm{C}$ for $30 \mathrm{sec}$, annealing at $47^{\circ} \mathrm{C}$ for $1 \mathrm{~min}(\mathrm{FOXG1})$ or $47^{\circ} \mathrm{C}$ for $30 \mathrm{sec}$ (D-Loop), elongation at $72^{\circ} \mathrm{C}$ for $30 \mathrm{sec}$ and final extension at $72^{\circ} \mathrm{C}$ for $5 \mathrm{~min}$. The relative mRNA expression level of FOXG1 was measured using the $2^{-\Delta \Delta \mathrm{Cq}}$ method (21). GAPDH was used as internal controls for FOXG1. The mtDNA copy number was calculated as the ratio of mitochondrial D-Loop to $18 \mathrm{~S}$ rRNA (22). The primer sequences (Invitrogen; Thermo Fisher Scientific, Inc.) for RT-qPCR are shown in Table I.

Western blot analysis. RIPA buffer (Cell Signaling Technology, Inc.) was used to obtain total protein from tissues or cells. A BCA assay kit (Pierce; Thermo Fisher Scientific, 
Inc.) was used to determine the protein concentration. Protein samples $(30 \mu \mathrm{g})$ were separated via $10 \%$ SDS-PAGE and then transferred onto PVDF membranes. The PVDF membranes were blocked with 5\% non-fat milk in $0.1 \%$ TBS-Tween-20 for $1 \mathrm{~h}$ at room temperature. Next, the PVDF membranes were incubated with primary antibodies [FOXG1, cat. no. ab196868; N-cadherin, cat. no. ab18203; Snail, cat. no. ab229701; caspase-9, cat. no. ab219590; heat shock protein (HSP) 60, cat. no. ab190828; 1:1,000, all from Abcam; Bax, cat. no. 5023; Bcl-2, cat. no. 3498; cleaved poly(ADP-ribose) polymerase 1 (PARP), cat. no. 9185; E-cadherin, cat. no. 3195; caspase-3, cat. no. 14220; caspase-8, cat. no. 4790; succinate dehydrogenase complex flavoprotein subunit A (SDHA), cat. no. 11998; pyruvate dehydrogenase (PDH), cat. no. 3205; cleaved caspase-3, cat. no. 9654; cleaved caspase-8, cat. no. 9496; cleaved caspase-9, cat. no. 20750; 1:1,000, all from Cell Signaling Technology, Inc.; PARP, cat. no. SAB4500487; 1:1,000, Sigma-Aldrich; Merck KGaA) overnight at $4^{\circ} \mathrm{C}$. The PVDF membranes were then incubated with horseradish peroxidase-conjugated goat polyclonal anti-rabbit IgG secondary antibodies (cat. no. ab150077; 1:2,000; Abcam) for $1 \mathrm{~h}$ at room temperature. Finally, the protein bands were visualized using an ECL reagent (Pierce; Thermo Fisher Scientific, Inc.). The intensity of protein bands were quantified using the Image Lab Software (V3.0; Bio-Rad Laboratories, Inc.).

MTT assay. SUNE-1 and C666-1 cells (1x10 cells/well) were seeded in 96-well plates. Next, the cells were incubated in fresh RPMI-1640 medium for $24,48,72$ or $96 \mathrm{~h}$ at $37^{\circ} \mathrm{C}$. Then, MTT solution $(10 \mu \mathrm{l})$ was added to each well, and the cells were cultured for $4 \mathrm{~h}$ in the incubator at $37^{\circ} \mathrm{C}$. Subsequently, the cells were incubated with DMSO $(150 \mu \mathrm{l})$ for $15 \mathrm{~min}$ at $37^{\circ} \mathrm{C}$. A microplate reader (Bio-Rad Laboratories, Inc.) was used to measure the optical density value at $450 \mathrm{~nm}$.

5-Ethynyl-20-deoxyuridine (EdU) assays. An EdU labelling/detection kit (Guangzhou RiboBio Co., Ltd.) was used to assess cell proliferation. Briefly, after transfection for $48 \mathrm{~h}$, the cells were incubated with $50 \mu \mathrm{M}$ EdU labelling medium for $2 \mathrm{~h}$ at $37^{\circ} \mathrm{C}$. Next, the cells were fixed with $4 \%$ paraformaldehyde for $25 \mathrm{~min}$ at room temperature and treated with $0.5 \%$ Triton $\mathrm{X}-100$ for $15 \mathrm{~min}$ at room temperature. Then, the cells were incubated with $1 \mathrm{X}$ Apollo reaction reagents (15 $\mu \mathrm{l}$ ) for $25 \mathrm{~min}$ at room temperature and stained with DAPI solution for $10 \mathrm{~min}$ at room temperature. Finally, the number of EdU-positive cells was examined under a fluorescent microscope at a magnification of $\mathrm{x} 100$, and the percentage of EdU-positive cells was counted from five random fields.

Wound healing assay. After transfection for $48 \mathrm{~h}$, the cells (1x106 cells/well) were seeded in 6-well plates and cultured in RPMI-1640 medium containing 10\% FBS to reach $90 \%$ confluence. A sterile $200-\mu 1$ pipette tip was used to create wounded monolayers, and the cells were cultured in serum-free medium for $48 \mathrm{~h}$ at $37^{\circ} \mathrm{C}$. Images of the monolayer wound were imaged at 0 and $48 \mathrm{~h}$ under an Olympus CKX53 microscope (Olympus Corporation) at a magnification of $\mathrm{x} 200$, and the migratory ability was analyzed using ImageJ software (V1.8.0.112; National Institutes of Health) from three randomly chosen fields.
Table I. Primers sequences for reverse transcription-quantitative PCR.

\begin{tabular}{ll}
\hline Primers & \multicolumn{1}{c}{ Sequences (5'-3') } \\
\hline FOXG1-F & GGAATTCAACATITCCTCCAAGGACACA \\
FOXG1-R & CGGGATCCGGGTFGCTAGAGCCTGGTAAT \\
GAPDH-F & CGGGAAACTGTGGCGTGAT \\
GAPDH-R & AGTGGGTGTCGCTGTFGAAGT \\
D-Loop-F & GATTTGGGTACCACCCAAGTATTG \\
D-Loop-R & AATATTCATGGTGGCTGGCATGTA \\
18S rRNA-F & TCTCCTACTTGGATAACTGTGG \\
18S rRNA-R & GGCGACTACCATCGAAAGTTG \\
\hline
\end{tabular}

F, forward; R, reverse; FOXG1, forkhead-box gene 1.

Transwell invasion assay. The cell invasive ability was detected using 24-well Transwell chambers (pre-coated with Matrigel for $1 \mathrm{~h}$ at $37^{\circ} \mathrm{C}$; Corning, Inc.). In brief, after transfection for $48 \mathrm{~h}$, cells $\left(2 \times 10^{4}\right.$ cells/well) were resuspended in $200 \mu \mathrm{l}$ serum-free medium and then added into the upper chambers. Next, $500 \mu 1$ RPMI-1640 medium containing 20\% FBS was added into the lower chambers. After incubation for $48 \mathrm{~h}$ at $37^{\circ} \mathrm{C}$, cells on the upper surface were wiped using a cotton swab, and the cells were fixed with $4 \%$ paraformaldehyde for $10 \mathrm{~min}$ at room temperature and stained with $0.1 \%$ crystal violet for $15 \mathrm{~min}$ at room temperature. Finally, the number of invasive cells was counted from three random fields under an inverted light microscope at a magnification of x 200 .

Cell apoptosis assay. After transfection for $48 \mathrm{~h}$, the Annexin V-FITC Apoptosis Detection kit (Sigma-Aldrich; Merck KGaA) was used to detect cell apoptosis. Cells were harvested with $0.25 \%$ trypsin and resuspended in binding buffer. Subsequently, the cells were incubated with PI $(5 \mu \mathrm{l})$ and Annexin V-FITC (2.5 $\mu \mathrm{l})$ for $20 \mathrm{~min}$ at room temperature in the dark. The cells were washed with cold PBS, and then flow cytometry (FACScan ${ }^{\mathrm{TM}}$; BD Biosciences) equipped with CellQuest software (V6.0; BD Biosciences) was conducted to calculate the proportion of apoptotic cells.

Measurement of ATP/ADP ratio. The ATP/ADP ratio was measured using the ADP/ATP ratio assay kit (Abcam). After transfection for $48 \mathrm{~h}$, the cells $\left(5 \times 10^{4}\right)$ were incubated with nucleotide-releasing buffer $(200 \mu \mathrm{l})$ for $10 \mathrm{~min}$ at room temperature. Next, the cells were treated with ATP monitoring enzyme $(10 \mu \mathrm{l})$ at room temperature for $10 \mathrm{~min}$ and ATP levels were measured immediately (A). ADP levels were measured (B), then cells were treated with ADP converting enzyme $(10 \mu \mathrm{l})$ at room temperature for $5 \mathrm{~min}$ and ADP levels were measured (C). Finally, the ATP/ADP ratio was calculated as follows: $\mathrm{A} /(\mathrm{C}-\mathrm{B})$.

Detection of mitochondrial membrane potential (MMP). After transfection for $48 \mathrm{~h}$, the cells $\left(5 \times 10^{5}\right)$ were grown in a medium containing $10 \mu \mathrm{g} / \mathrm{ml}$ 5,5',6,6 '-Tetrachloro-1,1',3,3'tetraethyl-benzimidazolylcarbocyanine iodide (Thermo Fisher Scientific, Inc.). After incubation for $30 \mathrm{~min}$ at $37^{\circ} \mathrm{C}$ in the dark, the cells were washed using PBS and flow cytometry (FACScan ${ }^{\mathrm{TM}}$; 
A

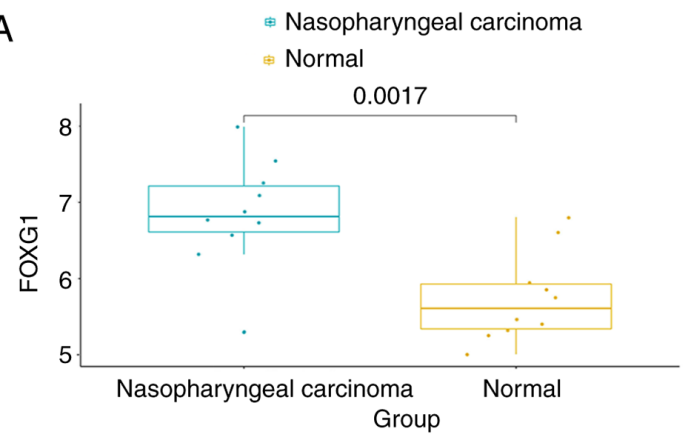

C

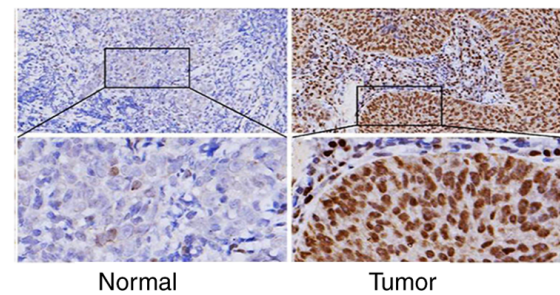

B

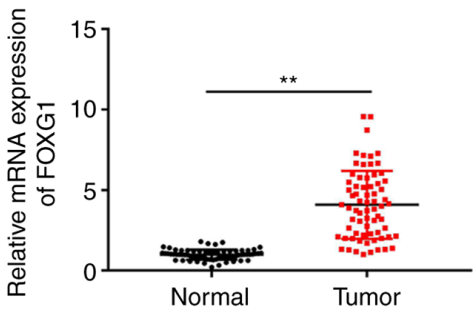

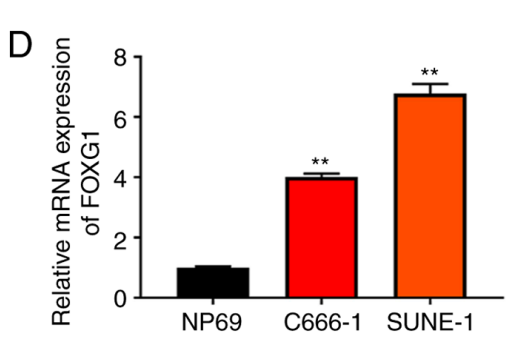

E
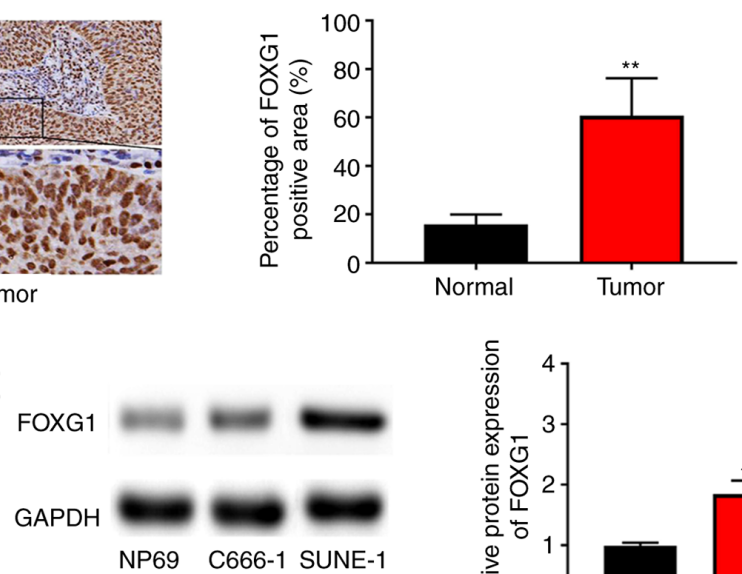

NP69

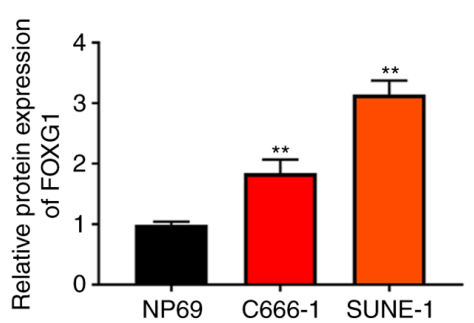

Figure 1. FOXG1 expression is upregulated in NPC tissues and cells. (A) FOXG1 expression in NPC tissues and normal tissues was analyzed from The Cancer Genome Atlas data. (B) FOXG1 expression in NPC tissues and para-carcinoma tissues (Normal) was detected via RT-qPCR. (C) FOXG1 expression in NPC tissues and para-carcinoma tissues (Normal) was detected via immunohistochemistry (magnification, $\mathrm{x} 100$ and $\mathrm{x} 400$ ). (D) FOXG1 mRNA expression in NPC cells (C666-1 and SUNE-1) and NP69 cells was evaluated using RT-qPCR. (E) FOXG1 protein expression in NPC cells (C666-1 and SUNE-1) and NP69 cells were measured via western blotting. ${ }^{* *} \mathrm{P}<0.01$ vs. Normal tissues or NP69 cells. FOXG1, forkhead-box gene 1; NPC, nasopharyngeal cancer; RT-qPCR, reverse transcription-quantitative PCR.

BD Biosciences) equipped with CellQuest software (V6.0; BD Biosciences) was used to detect changes in MMP.

Statistical analysis. All experiments were repeated $\geq 3$ times, and the data are expressed as the mean \pm SD. GraphPad Prism 7.0 (GraphPad Software, Inc.) was used to perform statistical analyses. $\chi^{2}$ test was used to analyze the association between FOXG1 expression and clinic characteristics in patients with NPC. An unpaired Student's t-test was used for comparison between two groups, and one-way ANOVA with Tukey's post-hoc test was used for comparison among $\geq 3$ groups. $\mathrm{P}<0.05$ was considered to indicate a statistically significant difference.

\section{Results}

FOXG1 expression is upregulated in NPC tissues and cells. Analysis of GEO dataset (GSE12452) revealed that FOXG1 expression in NPC tissues was upregulated compared with that in normal tissues (Fig. 1A). To examine the function of FOXG1 in NPC progression, FOXG1 expression was first measured in NPC tissues and para-carcinoma tissues (Normal) via RT-qPCR and IHC. As shown in Fig. 1B and C, FOXG1 expression in NPC tissues was higher compared with that in normal tissues. According to the median mRNA expression of FOXG1, patients with NPC were divided into low and high expression groups. It was found that FOXG1 expression was associated with distant metastasis and TNM stage, while there was no significant association with sex, smoking, EBV infection and age (Table II).

Next, FOXG1 expression in NPC cells (C666-1 and SUNE-1) and NP69 cells was evaluated using RT-qPCR and western blotting. As presented in Fig. 1D and E, FOXG1 expression was upregulated in NPC cells compared with that in NP69 cells.

FOXG1 promotes the proliferation of NPC cells. To investigate the effects of FOXG1 in NPC, SUNE-1 and C666-1 cells were transfected with siRNA-FOXG1 and pcDNA3.1-FOXG1, respectively. Transfection efficiency was assessed using RT-qPCR. As presented in Fig. 2A, FOXG1 expression in the si1-FOXG1 and si2-FOXG1groups was lower compared with that in the control and si-NC groups, and FOXG1 expression in the pcDNA3.1-FOXG1 group was higher compared with that in the control and pcDNA3.1-NC groups. These results indicated that transfection had been successful. Subsequently, cell proliferation was detected using MTT and EdU assays. It was found that knockdown of FOXG1 inhibited the proliferation of SUNE-1 cells compared with the control and si-NC groups, while overexpression of FOXG1 promoted the proliferation of C666-1 cells compared with the control and pcDNA3.1-NC groups (Fig. 2B and C). 

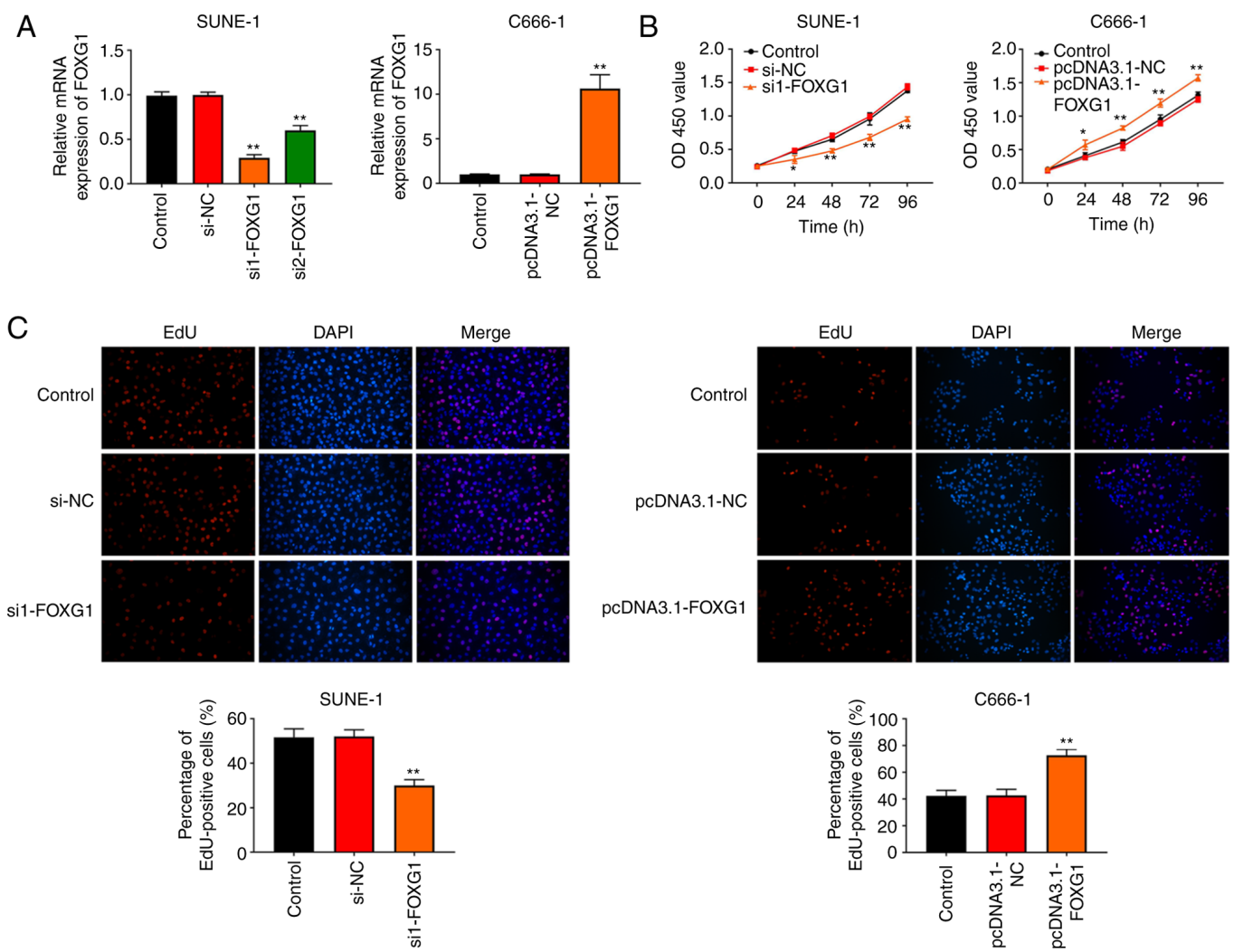

Figure 2. FOXG1 promotes the proliferation of nasopharyngeal cancer cells. (A) FOXG1 expression in SUNE-1 and C666-1cells was evaluated using reverse transcription-quantitative PCR after transfection with knockdown or overexpression of FOXG1, respectively. (B) Cell proliferation was detected using an MTT assay. (C) Cell proliferation was detected using an EdU assay (magnification, $\mathrm{x} 100$ ). ${ }^{*} \mathrm{P}<0.05,{ }^{* *} \mathrm{P}<0.01$ vs. Control, si-NC or pcDNA3.1-NC group. NC, negative control; si, small interfering RNA; FOXG1, forkhead-box gene 1; EdU, 5-Ethynyl-20-deoxyuridine; OD, optical density.

Table II. Association between FOXG1 expression and clinicopathological characteristics of patients with nasopharyngeal cancer.

\begin{tabular}{lcrrr}
\hline & & \multicolumn{2}{c}{$\begin{array}{c}\text { FOXG1 } \\
\text { expression }\end{array}$} & \\
\cline { 3 - 4 } Characteristics & Number of cases & High & Low & P-value \\
\hline Sex & & & & 0.112 \\
$\quad$ Male & 50 & 28 & 22 & \\
$\quad$ Female & 20 & 7 & 13 & \\
Age, years & & & & 0.632 \\
$<50$ & 34 & 18 & 16 & \\
$\geq 50$ & 36 & 17 & 19 & \\
Smoking & & & & 0.212 \\
$\quad$ Yes & 45 & 25 & 20 & \\
$\quad$ No & 25 & 10 & 15 & \\
EBV infection & & & & 0.147 \\
$\quad$ Negative & 40 & 23 & 17 & \\
$\quad$ Positive & 30 & 12 & 18 & \\
Distant metastasis & & & & $0.005^{\mathrm{a}}$ \\
$\quad$ Yes & 23 & 17 & 6 & \\
$\quad$ No & 47 & 18 & 29 & \\
TNM stage & & & & $0.003^{\mathrm{a}}$ \\
I-II & 24 & 6 & 18 & \\
III-IV & 46 & 29 & 17 & \\
\hline
\end{tabular}

${ }^{a} \mathrm{P}<0.01$ vs. FOXG1 high expression group. FOXG1, forkhead-box gene 1.
FOXG1 promotes the migration, invasion andepithelial-mesenchymal transition (EMT) of NPC cells. To investigate the role of FOXG1 in migration and invasion of NPC cells, cells were detected via wound healing and Transwell assays. The results demonstrated that knockdown of FOXG1 inhibited the migration and invasion of SUNE-1 cells, whereas the overexpression of FOXG1 promoted the migration and invasion of C666-1 cells (Fig. 3A and B).

Subsequently, western blotting was conducted to detect the expression levels of EMT-related proteins (N-cadherin, Snail and E-cadherin) to further determine the molecular mechanism mediating the aggressive effect of FOXG1. It was identified that knockdown of FOXG1 decreased the protein expression levels of N-cadherin and Snail in SUNE-1 cells and increased the protein expression level of E-cadherin (Fig. 3C). Conversely, overexpression of FOXG1 increased the protein expression levels of N-cadherin and Snail in C666-1 cells and decreased E-cadherin protein expression.

FOXG1 inhibits the apoptosis of NPC cells. To observe the effect of FOXG1 on cell apoptosis, flow cytometry analysis was performed on C666-1 and SUNE-1 cells. The results (Fig. 4A) demonstrated that knockdown of FOXG1 promoted the apoptosis of SUNE-1 cells, whereas overexpression of FOXG1 inhibited the apoptosis of C666-1 cells. Next, western blotting was performed to detect the expression levels of apoptosis-related proteins (Bax, Bcl-2, PARP, cleaved PARP, cleaved caspase- 3 , cleaved caspase- 8 , cleaved caspase-9, caspase-3, caspase-8 and caspase-9) in C666-1 and 

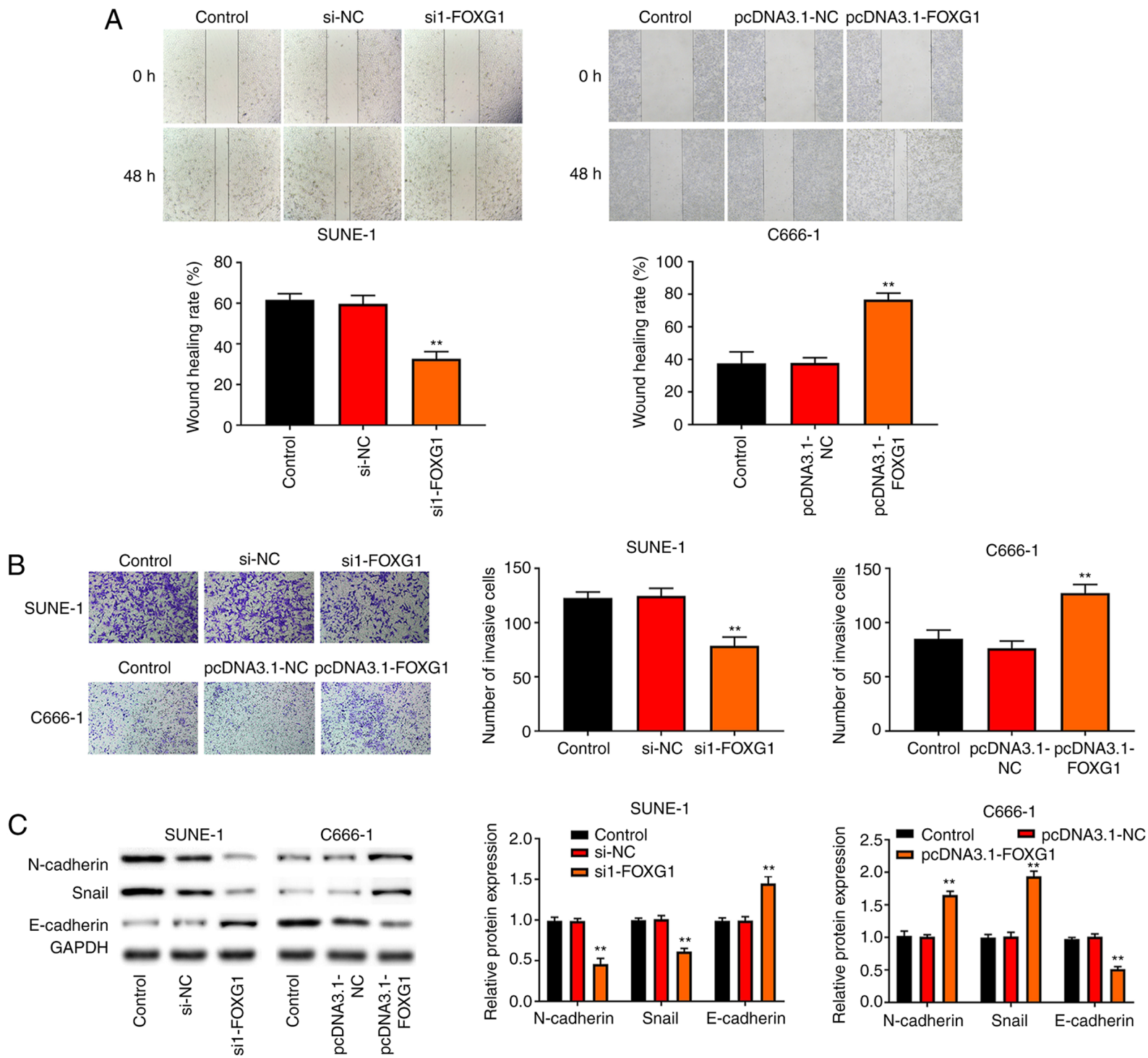

Figure 3. FOXG1 promotes the migration, invasion and EMT of NPC cells. (A) Migration of C666-1 and SUNE-1 cells was detected via wound healing assays (magnification, x200). (B) Invasion of C666-1 and SUNE-1 cells was detected using a Transwell assay (magnification, x200). (C) Western blot analysis was conducted to detect the expression levels of EMT-related proteins (N-cadherin, Snail and E-cadherin) in C666-1 and SUNE-1 cells. ${ }^{* * *} \mathrm{P}<0.01$ vs. Control, si-NC or pcDNA3.1-NC group. NC, negative control; si, small interfering RNA; FOXG1, forkhead-box gene 1; EMT, epithelial-mesenchymal transition.

SUNE-1 cells. As shown in Fig. 4B, knockdown of FOXG1 increased the expression levels of Bax/Bcl-2, PARP, cleaved PARP, cleaved caspase- 3 , cleaved caspase- 8 , cleaved caspase- 9 , caspase-3, caspase- 8 and caspase-9 in SUNE-1 cells. Notably, the opposite results were observed in the C666-1 cells with FOXG1 overexpression.

FOXG1 improves mitochondrial function in NPC cells. Mitochondrial dysfunction is reported to be associated with cancer cell death (19). To investigate whether FOXG1 was involved in the regulation of NPC mitochondrial function, the copy number of mtDNA was detected via RT-qPCR. As shown in Fig. 5A, knockdown of FOXG1 reduced the mtDNA copy number, whereas overexpression of FOXG1 increased the mtDNA copy number. Next, the ATP/ADP ratio was measured, and it was found that knockdown of FOXG1 resulted in a decreased ATP/ADP ratio, but overexpression of FOXG1 resulted in an increased ATP/ADP ratio (Fig. 5B). Moreover, knockdown of FOXG1 decreased the Red/Green ratio (indicative of MMP), while overexpression of FOXG1 increased the Red/Green ratio (Fig. 5C). Notably, the western blotting results revealed that knockdown of FOXG1 decreased the expression levels of mitochondrial markers (SDHA, HSP60 and PDH) in SUNE-1 cells, while the opposite results were observed in C666-1 cells with FOXG1 overexpression (Fig. 5D).

\section{Discussion}

It is well known that NPC is one of the most common malignant head and neck cancer types and lead to $\sim 50,800$ deaths worldwide in $2012(3,23)$. Previous studies have reported that FOXG1 exerted antitumor or carcinogenic effects in the progression of various cancer types $(12,24,25)$. In the present study, FOXG1 expression was upregulated in NPC tissues and cells, and FOXG1 expression was associated with distant metastasis and TNM stage. Moreover, knockdown of FOXG1 inhibited the proliferation, migration, invasion, EMT and 

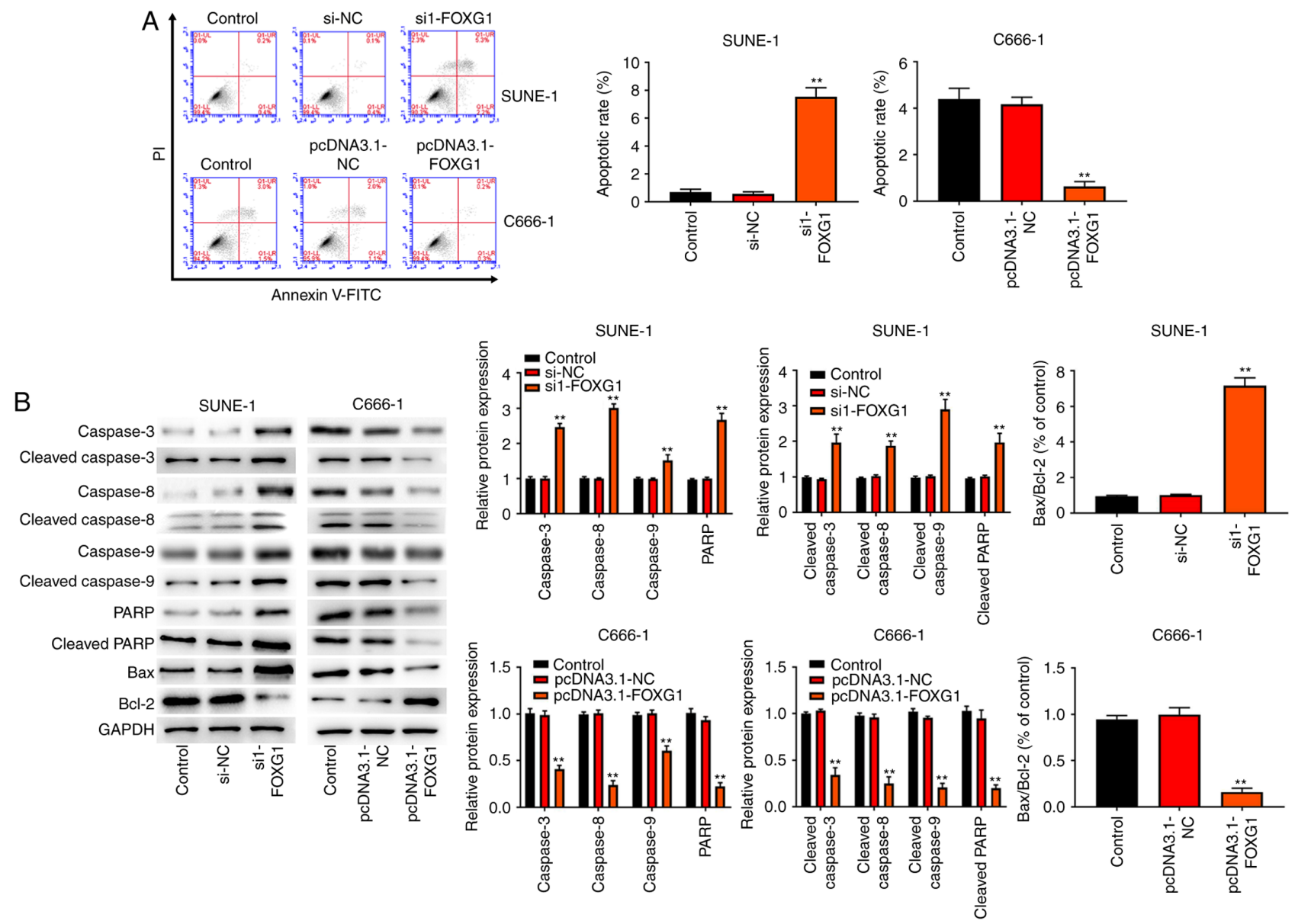

Figure 4. FOXG1 inhibits the apoptosis of NPC cells. (A) Flow cytometry analysis was used to detect the apoptosis of C666-1 and SUNE-1 cells. (B) Western blot analysis was conducted to detect the expression levels of apoptosis-related proteins (Bax, Bcl-2, PARP, cleaved PARP, caspase-3, cleaved caspase-3, caspase-8, cleaved caspase-8, cleaved caspase-9 and caspase-9) in C666-1 and SUNE-1 cells. ${ }^{* *} \mathrm{P}<0.01$ vs. Control, si-NC or pcDNA3.1-NC group. NC, negative control; si, small interfering RNA; FOXG1, forkhead-box gene 1; PARP, poly(ADP-ribose) polymerase 1.

mitochondrial function of SUNE-1 cells, as well as promoted cell apoptosis. Notably, the opposite results were observed in the C666-1 cells with FOXG1 overexpression.

FOXG1 participates in the proliferation and differentiation of various cells, and its dysregulated expression can cause the occurrence and development of different diseases (26-29). It has been reported that FOXG1 can induce the carcinogenic transformation of chicken embryo fibroblasts, indicating that FOXG1 may act as an oncogene in cancer $(30,31)$. Adesina et al (10) revealed that FOXG1 expression was upregulated in hepatoblastoma, while Chan et al (11) reported that FOXG1 was upregulated in ovarian cancer, and its expression level was positively correlated with ovarian cancer stage. In addition, a study by Chen et al (32) indicated that FOXG1 expression was elevated in glioma tissues and its expression was associated with glioma grade. The present study also demonstrated that FOXG1 expression was upregulated in NPC tissues and cells, and was associated with distant metastasis and TNM stage, which was consistent with a previous study (32). Taken together, these results indicate that FOXG1 may serve a role in the carcinogenesis of NPC.

In recent years, previous studies have reported that the members of the FOX transcription factor family serve an important role in the development of tumors and participate in the regulation of various malignant biological phenotypes of tumors $(33,34)$. The overexpression of FOXG1 has been shown to suppress the TGF- $\beta /$ Smad pathway induced-p $21^{\mathrm{WAF} / \mathrm{CIP} 1}$ expression and promote the proliferation of ovarian cancer cells (11). Verginelli et al (9) also observed that knockdown of FOXG1 inhibited the proliferation of brain tumor-initiating cells. Moreover, Chen et al (32) reported that knockdown of FOXG1 inhibited cell proliferation and promoted glioma cell apoptosis. In the present study, knockdown of FOXG1 inhibited proliferation and promoted apoptosis of SUNE-1 cells, while overexpression of FOXG1 promoted proliferation and inhibited apoptosis of C666-1 cells.

Apoptosis is regarded as a promising treatment for cancer, and the activation of caspases serves important parts in the process (35). The death receptor-mediated caspase- 8 and the mitochondria-dependent caspase-9 pathways are the main caspase-dependent pathways in apoptosis (36). Furthermore, the activation of caspase- 9 and caspase- 8 results in the activation of caspase-3 $(37,38)$. PARP, a downstream substrate of caspase-3, can directly affect cell apoptosis (39). Bax, a member of the Bcl-2 family, is a pro-apoptotic protein (40), while it has been shown that a high expression of Bcl-2 (an anti-apoptotic protein) could prevent cell apoptosis in cancer (41). Therefore, cell apoptosis is affected by the ratio of $\mathrm{Bax} / \mathrm{Bcl}-2$ (42). Zhang et al (43) confirmed that the overexpression of forkhead box protein O1 (FOXO1; a downstream target 

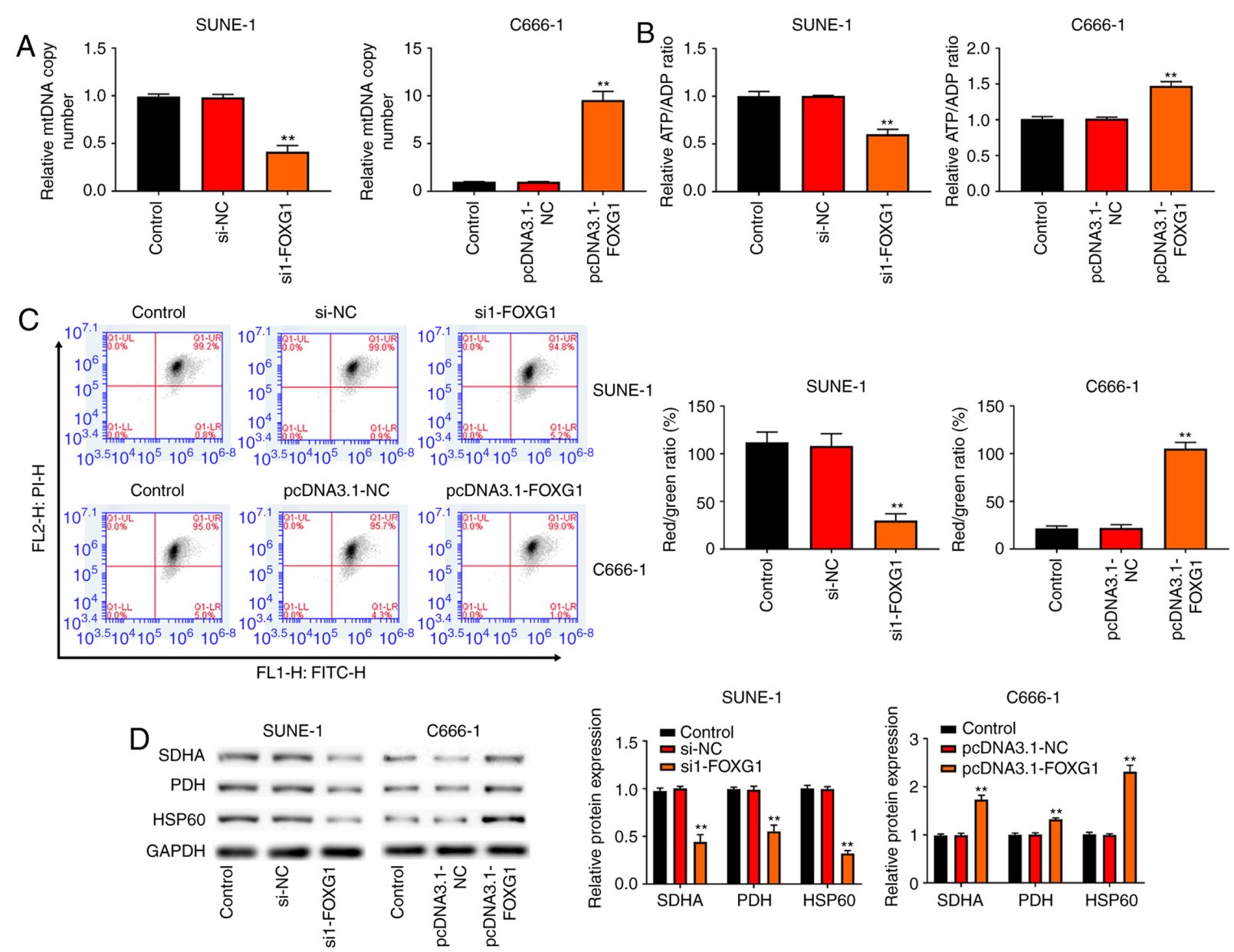

Figure 5. FOXG1 improves mitochondrial function in NPC cells. (A) The copy number of mitochondrial DNA in C666-1 and SUNE-1 cells was detected via reverse transcription-quantitative PCR. (B) Relative ATP/ADP ratio in C666-1 and SUNE-1 cells. (C) Mitochondrial membrane potential was detected via flow cytometry; red fluorescent mitochondria was found in the upper right quadrant and green fluorescent mitochondria in the lower right quadrant; decreased Red/Green ratio represented a decrease in mitochondrial membrane potential. (D) Expression levels of mitochondrial markers (SDHA, HSP60 and PDH) in C666-1 and SUNE-1 cells were detected via western blot analysis. ${ }^{* *} \mathrm{P}<0.01$ vs. Control, si-NC or pcDNA3.1-NC group. NC, negative control; si, small interfering RNA; FOXG1, forkhead-box gene 1; SDHA, succinate dehydrogenase complex flavoprotein subunit A; PDH, pyruvate dehydrogenase; HSP60, heat shock protein 60.

of FOXG1) induced cell-cycle arrest and apoptosis, as well as the upregulation of caspases- 3 and caspases- 9 expression in cervical cancer. The present study demonstrated that knockdown of FOXG1 increased the expression levels of Bax/Bcl-2, PARP, cleaved PARP, cleaved caspase-3, cleaved caspase-8, cleaved caspase-9, caspase-3, caspase- 8 and caspase- 9 in SUNE-1 cells, while the opposite results were observed in C666-1 cells. In summary, these findings indicate that FOXG1 promotes cell proliferation and inhibits apoptosis in NPC cells.

Distant metastases, rather than primary tumors, cause the majority of deaths associated with NPC (44). Metastasis is a multi-factor and multi-step dynamic process that involves a variety of gene regulatory cascade reactions $(45,46)$. The FOX gene family include types of transcription factors with diverse biological functions $(33,47)$. The current results suggested that knockdown of FOXG1 inhibited the migration and invasion of SUNE-1 cells, whereas overexpression of FOXG1 promoted the migration and invasion of C666-1 cells. EMT is defined as the loss of epithelial morphology and acquisition of a mesenchymal phenotype, and it is usually considered as an important factor for promoting cell invasion and migration in malignant diseases $(48,49)$. In the present study, knockdown of FOXG1 decreased the protein expression levels of $\mathrm{N}$-cadherin and
Snail in SUNE-1 cells and increased the protein expression level of E-cadherin. By contrast, overexpression of FOXG1 increased the protein expression levels of $\mathrm{N}$-cadherin and Snail in C666-1 cells and decreased the protein expression level of E-cadherin. These findings suggest that FOXG1 promotes NPC metastasis by inducing EMT.

Mitochondria serve an important role in maintaining cellular energy homeostasis (50). These are the main consumers of oxygen and glucose and can produce sufficient ATP, which is necessary for cancer behaviors $(51,52)$. However, mitochondrial damage can impair the metabolism of cancer and activate the activity of mitochondria-related apoptosis $(53,54)$. In addition, injured mitochondria cannot produce sufficient energy, which is associated with the failure of cancer cells to adhere and invade (55). The change of mtDNA copy number is considered as an indicator of mitochondrial damage (56). Previous studies have reported that the decrease of mtDNA copy number is the result of the decrease of biogenesis $(57,58)$. Furthermore, MMP is a marker for evaluating the biological function of mitochondria, and a decrease of MMP indicates mitochondrial biological dysfunction (59-61). Chen et al (62) revealed that the mitochondrial dysfunction, including reactive oxygen species production and reduction of MMP, could be 
caused by the overexpression of FOXO1. In the present study, it was found that knockdown of FOXG1 reduced the mtDNA copy number, ATP/ADP ratio and MMP, while overexpression of FOXG1 increased the mtDNA copy number, ATP/ADP ratio and MMP.

SDHA, a subunit of succinate dehydrogenase, participates in the tricarboxylic acid cycle and oxidative phosphorylation, and serves an important role in the process of cell energy metabolism $(63,64)$. PDH can transform pyruvate into acetyl-CoA and regulate energy metabolism of cells (65), while HSP60, a mitochondrial protein, serves an important role in maintaining mitochondrial integrity and ATP generation (66). In the present study, knockdown of FOXG1 decreased the expression levels of mitochondrial markers (SDHA, HSP60 and PDH) in SUNE-1 cells, while the opposite results were obtained in C666-1 cells. These data suggest that FOXG1 improves mitochondrial function in NPC cells.

The present study had certain limitations. Firstly, the prognosis of FOXG1 was not assessed and the detailed mechanism of FOXG1 in NPC progression requires further investigated. In vivo assays are necessary to verify the present conclusions.

In conclusion, the present study demonstrated that FOXG1 expression was upregulated in NPC tissues and cells, and it was associated with distant metastasis and TNM stage. In addition, FOXG1 enhanced cell proliferation, migration and invasion, induced EMT and improved mitochondrial function in NPC cells. These findings may provide further insights into the interactive mechanism between FOXG1 and NPC.

\section{Acknowledgements}

Not applicable.

\section{Funding}

No funding was received.

\section{Availability of data and materials}

The datasets used and/or analyzed during the current study are available from the corresponding author on reasonable request.

\section{Authors' contributions}

CL designed the study. $\mathrm{HX}$ and $\mathrm{ZH}$ performed the research and analyzed the data. $\mathrm{HX}$ and $\mathrm{ZH}$ confirmed the authenticity of the raw data. HX wrote the paper. All authors read and approved the final manuscript.

\section{Ethics approval and consent to participate}

The protocol of this research has been approved by the Ethics Committee of Affiliated Hospital of The Second Affiliated Hospital of Kunming Medical University (approval no. KYDE201801012). All patients have signed written informed consent.

\section{Patient consent for publication}

Not applicable.

\section{Competing interests}

The authors declare that they have no competing interests.

\section{References}

1. Tang LL, Chen WQ, Xue WQ, He YQ, Zheng RS, Zeng YX and Jia WH: Global trends in incidence and mortality of nasopharyngeal carcinoma. Cancer Lett 374: 22-30, 2016.

2. Jemal A, Bray F, Center MM, Ferlay J, Ward E and Forman D: Global cancer statistics. CA Cancer J Clin 61: 69-90, 2011.

3. Ferlay J, Soerjomataram I, Dikshit R, Eser S, Mathers C, Rebelo M, Parkin DM, Forman D and Bray F: Cancer incidence and mortality worldwide: Sources, methods and major patterns in GLOBOCAN 2012. Int J Cancer 136: E359-E386, 2015.

4. Yu MC and Yuan JM: Epidemiology of nasopharyngeal carcinoma. Semin Cancer Biol 12: 421-429, 2002.

5. Peng H, Chen L, Chen Y-P, Li WF, Tang LL, Lin AH, Sun Y and Ma J: The current status of clinical trials focusing on nasopharyngeal carcinoma: A comprehensive analysis of ClinicalTrials. gov database. PLoS One 13: e0196730, 2018.

6. Chan JYW, To VSH, Wong STS and Wei WI: Radiation-induced squamous cell carcinoma of the nasopharynx after radiotherapy for nasopharyngeal carcinoma. Head Neck 36: 772-775, 2014

7. Katoh M and Katoh M: Human FOX gene family (Review). Int J Oncol 25: 1495-1500, 2004

8. Brancaccio M, Pivetta C, Granzotto M, Filippis C and Mallamaci A: Emx2 and Foxg1 inhibit gliogenesis and promote neuronogenesis. Stem Cells 28: 1206-1218, 2010.

9. Verginelli F, Perin A, Dali R, Fung KH, Lo R, Longatti P, Guiot MC, Del Maestro RF, Rossi S, di Porzio U, et al: Transcription factors FOXG1 and Groucho/TLE promote glioblastoma growth. Nat Commun 4: 2956, 2013.

10. Adesina AM, Nguyen Y,GuanaratneP,Pulliam J,Lopez-Terrada D, Margolin J and Finegold M: FOXG1 is overexpressed in hepatoblastoma. Hum Pathol 38: 400-409, 2007.

11. Chan DW, Liu VW, To RM, Chiu PM, Lee WY, Yao KM, Cheung AN and Ngan HY: Overexpression of FOXG1 contributes to TGF- $\beta$ resistance through inhibition of $\mathrm{p} 21^{\mathrm{WAF} / \mathrm{CIP1}}$ expression in ovarian cancer. Br J Cancer 101: 1433-1443, 2009.

12. Seoane J, Le HV, Shen L, Anderson SA and Massagué J: Integration of Smad and forkhead pathways in the control of neuroepithelial and glioblastoma cell proliferation. Cell 117: 211-223, 2004.

13. Myatt SS and Lam EW: The emerging roles of forkhead box (Fox) proteins in cancer. Nat Rev Cancer 7: 847-859, 2007.

14. Hirschey MD, DeBerardinis RJ, Diehl AME, Drew JE, Frezza C, Green MF, Jones LW, Ko YH, Le A, Lea MA, et al; Target Validation Team: Dysregulated metabolism contributes to oncogenesis. Semin Cancer Biol 35 (Suppl 1): S129-S150, 2015.

15. Ru P, Williams TM, Chakravarti A and Guo D: Tumor metabolism of malignant gliomas. Cancers (Basel) 5: 1469-1484, 2013.

16. Attardi G and Schatz G: Biogenesis of mitochondria. Annu Rev Cell Biol 4: 289-333, 1988.

17. Li HJ, Sun XM, Li ZK, Yin QW, Pang H, Pan JJ, Li X and Chen W: LncRNA UCA1 promotes mitochondrial function of bladder cancer via the MiR-195/ARL2 signaling pathway. Cell Physiol Biochem 43: 2548-2561, 2017.

18. Song IS, Jeong YJ, Jeong SH, Kim JE, Han J, Kim TH and Jang SW: Modulation of mitochondrial ER $\beta$ expression inhibits triple-negative breast cancer tumor progression by activating mitochondrial function. Cell Physiol Biochem 52: 468-485, 2019.

19. Zhang X, Li F, Cui Y, Liu S and Sun H: Mst1 overexpression combined with Yap knockdown augments thyroid carcinoma apoptosis via promoting MIEF1-related mitochondrial fission and activating the JNK pathway. Cancer Cell Int 19: 143, 2019.

20. Ritchie ME, Phipson B, Wu D, Hu Y, Law CW, Shi W and Smyth GK: limma powers differential expression analyses for RNA-sequencing and microarray studies. Nucleic Acids Res 43: e47, 2015.

21. Livak KJ and Schmittgen TD: Analysis of relative gene expression data using real-time quantitative PCR and the 2(-Delta Delta C(T)) method. Methods 25: 402-408, 2001.

22. Luo C, Li Y, Wang H, Feng Z, Li Y, Long J and Liu J: Mitochondrial accumulation under oxidative stress is due to defects in autophagy. J Cell Biochem 114: 212-219, 2013. 
23. Gong Z, Zhang S, Zeng Z, Wu H, Yang Q, Xiong F, Shi L, Yang J, Zhang W, Zhou Y, et al: LOC401317, a p53-regulated long non-coding RNA, inhibits cell proliferation and induces apoptosis in the nasopharyngeal carcinoma cell line HNE2. PLoS One 9: e110674, 2014.

24. Zeng F, Xue M, Xiao T, Li Y, Xiao S, Jiang B and Ren C: MiR-200b promotes the cell proliferation and metastasis of cervical cancer by inhibiting FOXG1. Biomed Pharmacother 79: 294-301, 2016.

25. Li JV, Chien CD, Garee JP, Xu J, Wellstein A and Riegel AT: Transcriptional repression of AIB1 by FoxG1 leads to apoptosis in breast cancer cells. Mol Endocrinol 27: 1113-1127, 2013.

26. Pancrazi L, Di Benedetto G, Colombaioni L, Della Sala G, Testa G Olimpico F, Reyes A, Zeviani M, Pozzan T and Costa M: Foxg1 localizes to mitochondria and coordinates cell differentiation and bioenergetics. Proc Natl Acad Sci USA 112: 13910-13915, 2015.

27. Manoranjan B, Venugopal C, McFarlane N, Doble BW, Dunn SE, Scheinemann K and Singh SK: Medulloblastoma stem cells: Modeling tumor heterogeneity. Cancer Lett 338: 23-31, 2013.

28. De Filippis R, Pancrazi L, Bjørgo K, Rosseto A, Kleefstra T, Grillo E, Panighini A, Cardarelli F, Meloni I, Ariani F, et al: Expanding the phenotype associated with FOXG1 mutations and in vivo FoxG1 chromatin-binding dynamics. Clin Genet 82: 395-403, 2012.

29. Mariani J, Coppola G, Zhang P, Abyzov A, Provini L, Tomasini L, Amenduni M, Szekely A, Palejev D, Wilson M, et al: FOXG1-dependent dysregulation of GABA/glutamate neuron differentiation in autism spectrum disorders. Cell 162: 375-390, 2015.

30. Chang HW, Li J and Vogt PK: Domains of the qin protein required for oncogenic transformation. Oncogene 13: 441-444, 1996.

31. Li J, Thurm H, Chang HW, Iacovoni JS and Vogt PK: Oncogenic transformation induced by the Qin protein is correlated with transcriptional repression. Proc Natl Acad Sci USA 94: 10885-10888, 1997.

32. Chen J, Wu X, Xing Z, Ma C, Xiong W, Zhu X and He X: FOXG1 expression is elevated in glioma and inhibits glioma cell apoptosis. J Cancer 9: 778-783, 2018.

33. Laissue P: The forkhead-box family of transcription factors: Key molecular players in colorectal cancer pathogenesis. Mol Cancer 18 $5,2019$.

34. Li Y, Wang HQ, Wang AC, Li YX, Ding SS, An XJ and Shi HY: Overexpression of Forkhead box Q1 correlates with poor prognosis in papillary thyroid carcinoma. Clin Endocrinol (Oxf) 90: 334-342, 2019.

35. Li X, Qu Z, Jing S, Li X, Zhao C, Man S, Wang Y and Gao W: Dioscin-6'-O-acetate inhibits lung cancer cell proliferation via inducing cell cycle arrest and caspase-dependent apoptosis. Phytomedicine 53: 124-133, 2019.

36. Huang SH, Wu LW, Huang AC, Yu CC, Lien JC, Huang YP, Yang JS, Yang JH, Hsiao YP, Wood WG, et al: Benzyl isothiocyanate (BITC) induces $\mathrm{G} 2 / \mathrm{M}$ phase arrest and apoptosis in human melanoma A375.S2 cells through reactive oxygen species (ROS) and both mitochondria-dependent and death receptor-mediated multiple signaling pathways. J Agric Food Chem 60: 665-675, 2012.

37. Won YS and Seo KI: Lupiwighteone induces caspase-dependent and -independent apoptosis on human breast cancer cells via inhibiting PI3K/Akt/mTOR pathway. Food Chem Toxicol 135 $110863,2020$.

38. Lkhagvasuren $\mathrm{K}$ and Kim JK: Ziyuglycoside II induces caspases-dependent and caspases-independent apoptosis in human colon cancer cells. Toxicol In Vitro 59: 255-262, 2019.

39. Zeng Y, Zhang Z, Wang W, You L, Dong X, Yin X, Qu C and Ni J: Underlying mechanisms of apoptosis in HepG2 cells induced by polyphyllin I through Fas death and mitochondrial pathways. Toxicol Mech Methods 30: 397-406, 2020.

40. Nechushtan A, Smith CL, Hsu YT and Youle RJ: Conformation of the Bax C-terminus regulates subcellular location and cell death. EMBO J 18: 2330-2341, 1999.

41. Del Gaizo Moore V, Schlis KD, Sallan SE, Armstrong SA and Letai A: BCL-2 dependence and ABT-737 sensitivity in acute lymphoblastic leukemia. Blood 111: 2300-2309, 2008.

42. Bivik CA, Larsson PK, Kågedal KM, Rosdahl IK and Ollinger KM: UVA/B-induced apoptosis in human melanocytes involves translocation of cathepsins and Bcl-2 family members. J Invest Dermatol 126: 1119-1127, 2006.

43. Zhang B, Gui LS, Zhao XL, Zhu LL and Li QW: FOXO1 is a tumor suppressor in cervical cancer. Genet Mol Res 14: 6605-6616, 2015.

44. Torre LA, Bray F, Siegel RL, Ferlay J, Lortet-Tieulent J and Jemal A: Global cancer statistics, 2012. CA Cancer J Clin 65 : 87-108, 2015.

45. Pencheva N and Tavazoie SF: Control of metastatic progression by microRNA regulatory networks. Nat Cell Biol 15: 546-554, 2013.
46. Li Y, Zhou X, Liu J, Gao N, Yang R, Wang Q, Ji J, Ma L and He Q: Dihydroartemisinin inhibits the tumorigenesis and metastasis of breast cancer via downregulating CIZ1 expression associated with TGF- $\beta 1$ signaling. Life Sci 248: 117454, 2020.

47. Jin Y, Liang $Z$ and Lou H: The emerging roles of fox family transcription factors in chromosome replication, organization, and genome stability. Cells 9: 258, 2020.

48. Xia YY, Yin L, Tian H, Guo WJ, Jiang N, Jiang XS, Wu J, Chen M, $\mathrm{Wu} \mathrm{JZ}$ and He X: HMGA2 is associated with epithelial-mesenchymal transition and can predict poor prognosis in nasopharyngeal carcinoma. OncoTargets Ther 8: 169-176, 2015.

49. Thiery JP, Acloque H, Huang RYJ and Nieto MA: Epithelialmesenchymal transitions in development and disease. 139: 0-890,

50. Bai M, Chen H, Ding D, Song R, Lin J, Zhang Y, Guo Y, Chen S, Ding G, Zhang Y, et al: MicroRNA-214 promotes chronic kidney disease by disrupting mitochondrial oxidative phosphorylation. Kidney Int 95: 1389-1404, 2019.

51. Biernacki M, Ambrożewicz E, Gegotek A, Toczek M, Bielawska K and Skrzydlewska E: Redox system and phospholipid metabolism in the kidney of hypertensive rats after FAAH inhibitor URB597 administration. Redox Biol 15: 41-50, 2018.

52. Davidson SM, Arjun S, Basalay MV, et al: The 10th Biennial Hatter Cardiovascular Institute workshop: cellular protection - evaluating new directions in the setting of myocardial infarction, ischaemic stroke, and cardio-oncology. Basic Res Cardiol 113: 43, 2018.

53. Gonzalez NR, Liou R, Kurth F, Jiang H and Saver J: Antiangiogenesis and medical therapy failure in intracranial atherosclerosis. Angiogenesis 21: 23-35, 2018.

54. DeLeon-Pennell KY, Mouton AJ, Ero OK, Ma Y, Padmanabhan Iyer R, Flynn ER, Espinoza I, Musani SK, Vasan RS, Hall ME, et al: LXR/RXR signaling and neutrophil phenotype following myocardial infarction classify sex differences in remodeling. Basic Res Cardiol 113: 40, 2018.

55. Chandra M, Escalante-Alcalde D, Bhuiyan MS, Orr AW, Kevil C, Morris AJ, Nam H, Dominic P, McCarthy KJ, Miriyala S, et al: Cardiac-specific inactivation of LPP3 in mice leads to myocardial dysfunction and heart failure. Redox Biol 14: 261-271, 2018.

56. Sanyal T, Bhattacharjee $P$, Bhattacharjee $S$ and Bhattacharjee $P$. Hypomethylation of mitochondrial D-loop and ND6 with increased mitochondrial DNA copy number in the arsenic-exposed population. Toxicology 408: 54-61, 2018

57. Rice AC, Keeney PM, Algarzae NK, Ladd AC, Thomas RR and Bennett JP Jr: Mitochondrial DNA copy numbers in pyramidal neurons are decreased and mitochondrial biogenesis transcriptome signaling is disrupted in Alzheimer's disease hippocampi. J Alzheimers Dis 40: 319-330, 2014.

58. Wen SL, Zhang F and Feng S: Decreased copy number of mitochondrial DNA: A potential diagnostic criterion for gastric cancer. Oncol Lett 6: 1098-1102, 2013

59. Weber LW, Boll M and Stampfl A: Hepatotoxicity and mechanism of action of haloalkanes: Carbon tetrachloride as a toxicological model. Crit Rev Toxicol 33: 105-136, 2003.

60. Quarato G,Piccoli C, Scrima R and Capitanio N: Functional imaging of membrane potential at the single mitochondrion level: Possible application for diagnosis of human diseases. Mitochondrion 11: 764-773, 2011

61. Lugli E, Troiano L and Cossarizza A: Polychromatic analysis of mitochondrial membrane potential using JC-1. Curr Protoc Cytom Chapter 7: 32, 2007

62. Chen C, Luo Y, Su Y and Teng L: The vitamin D receptor (VDR) protects pancreatic beta cells against Forkhead box class O1 (FOXO1)-induced mitochondrial dysfunction and cell apoptosis. Biomed Pharmacother 117: 109170, 2019.

63. Sun F, Huo X, Zhai Y, Wang A, Xu J, Su D, Bartlam M and Rao Z: Crystal structure of mitochondrial respiratory membrane protein complex II. Cell 121: 1043-1057, 2005.

64. Liu X, Zhou Z, Wang Z, Li X, Lu G and Tong J: SDHA-mediated Warburg effect in malignantly transformed human bronchial epithelial cells following long-term exposure to radon. Environ Toxicol 35: 861-866, 2020

65. Eguchi K and Nakayama K: Prolonged hypoxia decreases nuclear pyruvate dehydrogenase complex and regulates the gene expression. Biochem Biophys Res Commun 520: 128-135, 2019.

66. Song E, Tang S, Xu J, Yin B, Bao E and Hartung J: Lenti-siRNA Hsp60 promote bax in mitochondria and induces apoptosis during heat stress. Biochem Biophys Res Commun 481: 125-131, 2016.

This work is licensed under a Creative Commons Attribution-NonCommercial-NoDerivatives 4.0 International (CC BY-NC-ND 4.0) License. 